\title{
Evaluation of the representation of Arctic sea ice in the U.K. Hadley Centre GCM
}

\author{
Douglas M. Smith, ${ }^{1}$ Claire Cooper, ${ }^{2}$ Duncan J. Wingham, ${ }^{1}$ Seymour W. Laxon ${ }^{1}$ \\ ${ }^{1}$ Department of Space and Climate Physics, Mullard Space Science Laboratory, University College London, \\ Holmbury St. Mary, Dorking, Surrey RH5 6.NT, U.K. \\ ${ }^{2}$ Hadley Centre for Climate Prediction and Research, Meteorological Office, London, Bracknell, Berkshire RGI2 2ST, U.K.
}

\begin{abstract}
The amount of Arctic sea ice predicted by the Hadley Centre Global Climate Model (GCM) is evaluated using 15 years of passive-microwave data. While the Hadley model reproduces the seasonal cycle reasonably well, it underestimates the total area of sea ice by more than $3 \times 10^{6} \mathrm{~km}^{2}$ for most of the year. In the winter months, most of the underestimate in ice area results from the prediction of far too little ice in Hudson Bay and the Sea of Okhotsk, leading to an excess of up to 0.2 PW heat input to the atmosphere from Hudson Bay alone. The surface-energy budget of Hudson Bay is investigated using a mixture of surface observations (POLES), satellite data (ATSR, SSM/I and ISCCP) and output from the Goddard Data Assimilation Office analysis. Flux adjustments of the order of $200 \mathrm{Wm}^{-2}$, resulting from anomalously high sea-surface temperatures in the Levitus (1982) climatology, are found to be the cause of the model's underestimation of sea ice in both Hudson Bay and the Sea of Okhotsk. The fact that flux adjustments based on an inaccurate climatology will produce errors, even if the model physics is correct, underlines the need both for improved climatologies and for models accurate enough not to require flux adjustment.
\end{abstract}

\section{INTRODUGTION}

Sea ice is capable of exerting a major influence on the Earth's climate for a number of reasons: cold, dense brine rejected during ice formation, particularly in the Labrador and Greenland Seas, is believed to have a significant effect on the global thermohaline ocean circulation (Aagaard and others, 1985); the turbulent transfer of sensible and latent heat between the ocean and atmosphere is reduced by more than two orders of magnitude in the presence of sea ice (Maykut, 1978); and the surface albedo of sea ice is an order of magnitude greater than that of open ocean, thus significantly altering the surface-radiation balance. Furthermore, the wellknown positive feedback between temperature and surface albedo (Ingram and others, 1989) is likely to amplify greenhouse-induced climate change. It is therefore essential that sea ice, and its interaction with the atmosphere and oceans, is properly represented in global climate models (GCMs).

This paper presents a preliminary evaluation of presentday Arctic sea ice predicted by the control run of the UK Hadley Centre GCM. The cause of significant errors in the modelled winter sea-ice distribution is identified by examining the components of the surface-energy budget governing ice formation, and implications for climate modelling are discussed.

\section{HADLEY GGM}

The Hadley GCM is a fully-coupled ice atmosphere ocean model with a resolution of $2.5^{\circ}$ latitude by $3.75^{\circ}$ longitude, 19 levels in the atmosphere, 20 layers in the ocean and 4 soil layers (Johns and others, 1997). This model is derived from that used in earlier studies (Murphy, 1995), but features completely revised atmospheric dynamics based on a different grid type, and significant changes to the ocean and seaice components.

In order to prevent climate drift arising from systematic model errors, the sea-surface temperature and salinity are relaxed back to climatological values. This is achieved by adding flux adjustments to the energy and fresh-water fluxes of the ocean (Sausen and others, 1988). Monthly mean flux adjustments were calculated at the end of the 510 year coupled spin-up as Newtonian-relaxation terms proportional to the differences between modelled sea-surface temperatures and salinities, and climatological values from Levitus (1982). These flux adjustments remained fixed in subsequent runs. Although the model would still reach an equilibrium state without flux adjustment, it would have an unrealistic climate, casting doubt on conclusions from climate-change experiments.

Sea-ice thermodynamics is based on the zero-layer model of Semtner (1976), with ice concentration parameterised according to Hibler (1979). Sea-ice dynamics is based on the simple scheme of Bryan (1969), in which ice thickness and concentration and snow depth are advected using the surface currents from the ocean model. Ice rheology is crudely parameterised by preventing convergence of ice once the depth reaches $4 \mathrm{~m}$.

Climatological model data used in this study were averaged over 15 years of the control run. 


\section{VALIDATION DATA}

\section{Sea-ice concentration}

Passive-microwave data from the Scanning Multichannel Microwave Radiometer (SMMR) and Special Sensor Microwave Imager (SSM/I) (National Snow and Ice Data Center, 1989) over a 15 year period from 1979 to 1994 were used to calculate monthly mean sea-ice concentration using the NASA/Team algorithm (Cavalieri and others, 1984).

\section{Data Assimilation Office (DAO)}

The DAO dataset (Schubert and others, 1993) was produced by assimilating rawinsonde reports, satellite retrievals of geopotential thickness, cloud-motion winds, and aircraft, ship and buoy reports with short-term model forecasts from the Goddard Earth Observing System (GEOS) GCM. This GCM was constrained at the surface by observed sea-surface temperature and soil moisture. Climatological monthly mean values were obtained by averaging eight years of data from 1986 to 1993 , and used in this study to evaluate the Hadley GCM surface-energy budget.

\section{Shortwave and longwave radiation}

In addition to the DAO fluxes, short wave- and longwave-radiative fluxes at the surface (calculated by the Goddard Institute of Space Sciences (GISS) radiative-transfer model incorporating measurements from the International Satellite Cloud Climatology Project (ISCCP) (Zhang and others, 1995) were obtained from GISS. Preliminary validation against surface measurements at Barrow, Alaska, and the South Pole indicates uncertainties of about $25 \mathrm{Wm}^{-2}$ in this dataset in polar regions (Rossow and Zhang, 1995). Comparison with the measurements by Fletcher (1965) of incoming longwave radiation over the central Arctic indicates an annual root mean-squared (rms) error (calculated as the rms difference of monthly means) of $23 \mathrm{Wm}^{-2}$ for the GISS/ ISCCP data and $53 \mathrm{Wm}^{-2}$ for the DAO data.

\section{Sensible heat flux}

Sensible heat flux $\left(F_{\mathrm{s}}\right)$ towards the surface was calculated in this study from the bulk aerodynamic formula

$$
F_{\mathrm{s}}=\rho_{\mathrm{a}} c_{\mathrm{p}} C_{\mathrm{H}} V\left(T_{\mathrm{a}}-T_{\mathrm{s}}\right)
$$

where $\rho_{\mathrm{a}}\left(1.2 \mathrm{~kg} \mathrm{~m}^{-3}\right)$ and $c_{\mathrm{p}}\left(3930 \mathrm{~J} \mathrm{~kg}^{-1} \mathrm{~K}^{-1}\right)$ are the density and specific-heat capacity of air, $V$ is the surface wind speed, $T_{\mathrm{a}}$ is the surface-air temperature, $T_{\mathrm{s}}$ is the surface temperature, and $C_{\mathrm{H}}$ is the sensible-heat transfer coefficient. In the Hadley model, $C_{\mathrm{H}}$ is calculated as a function of the atmospheric stability using the Monin-Obukhov similarity theory. In the absence of observed-stability information, however, $C_{\mathrm{H}}$ was taken in this study as a constant 0.00175 following Parkinson and Washington (1979).

In addition to the DAO output, the following data were used to calculate sensible heat fluxes. Monthly mean SSM/I wind speeds over the ocean were obtained from the Jet Propulsion Laboratory (Halpern and others, 1995) for the years 1989 92. Monthly mean surface-air temperatures from land stations, ship observations, Soviet North Pole drifting-ice stations and Arctic drifting buoys from 1979 to 1992 were obtained from the Polar Exchange at the Sea Surface (POLES) program, University of Washington, Seattle. Monthly mean sea-surface temperatures (SSTs) from the
Along-Track Scanning Radiometer (ATSR) (Zavody and others, 1995; Jones and others, 1996) between 1991 and 1995 were obtained from the Rutherford Appleton Laboratory.

Mean, minimum and maximum fluxes using the whole range of data sources were calculated in order to represent the uncertainty in the validation data. DAO air and sea-ice surface temperatures, however, appear to be too low compared with the POLES surface-air temperatures, resulting in anomalously large fluxes of sensible heat calculated using a mixture of the two. In the absence of accurate sea-ice surface temperatures, therefore, only the self-consistent DAO information was used to calculate sensible heat fluxes over consolidated sea ice. Comparison with the measurements by Fletcher (1965) indicate an annual rms error of $13 \mathrm{Wm}^{-2}$ for the sensible heat flux over consolidated ice in the central Arctic.

\section{Latent heat flux}

Latent heat flux $\left(F_{1}\right)$ towards the surface was calculated from the bulk aerodynamic formula

$$
F_{1}=\rho_{\mathrm{a}} L C_{\mathrm{E}} V\left(q_{\mathrm{a}}-q_{\mathrm{s}}\right)
$$

where $L$ is the latent heat of vaporisation $\left(2.5 \times 10^{6} \mathrm{~J} \mathrm{~kg}^{-1}\right)$ or of sublimation $\left(2.834 \times 10^{6} \mathrm{~J} \mathrm{~kg}^{-1}\right)$ depending on whether an ice cover exists, $C_{\mathrm{E}}$ is the latent heat exchange coefficient taken as 0.00175 following Parkinson and Washington (1979), and $q_{\mathrm{a}}$ is the surface-air specific humidity (from DAO). The surface-specific humidity $q_{\mathrm{s}}$ is related to the saturation vapour pressure $e_{\mathrm{s}}$ through the equation

$$
q_{\mathrm{s}}=\frac{\epsilon e_{\mathrm{s}}}{p-(1 .-\epsilon) e_{\mathrm{s}}}
$$

where $\epsilon=0.622$ is the ratio of the molecular weight of water vapour to that of dry air, $p\left(1.014 \times 10^{5} \mathrm{~Pa}\right)$ is the surface pressure, and $e_{\mathrm{s}}$ is given by (Parkinson and Washington, 1979)

$$
e_{\mathrm{s}}=611 \times 10^{a\left(T_{\mathrm{s}}-273.16\right) /\left(T_{\mathrm{s}}-b\right)}
$$

where the coefficients $(a, b)=(9.5,7.66)$ if an ice cover exists, or $(7.5,35.86)$ for open water. As with the sensible heat flux calculations, $T_{\mathrm{s}}$ was obtained from both DAO and ATSR. Comparison with the measurements by Fletcher (1965) indicate an annual $\mathrm{rms}$ error of $9 \mathrm{Wm}^{-2}$ for the latent heat flux over consolidated ice in the central Arctic.

\section{SEA ICE COMPARISON}

Figure 1 shows the 15 year mean, minimum and maximum annual cycle of total Arctic sea-ice area predicted by the Hadley GCM, compared with satellite observations. The Hadley GCM reproduces the seasonal cycle reasonably well, but underestimates the Arctic ice area by more than $3 \times 10^{6} \mathrm{~km}^{2}$ for most of the year.

The mean distribution of sea ice for March is shown in Figure 2. The Hadley GCM slightly overestimates the ice concentration in the Greenland Sea, possibly as a result of the crude advection parameterisation, but significantly underestimates the concentration in Hudson Bay, the Sea of Okhotsk and the Labrador Sea. Failure of the model to produce sea ice in Hudson Bay alone results in an excess of heat input to the atmosphere of up to $0.2 \mathrm{PW}$ during the winter.

In order to establish the cause of the underestimation of 


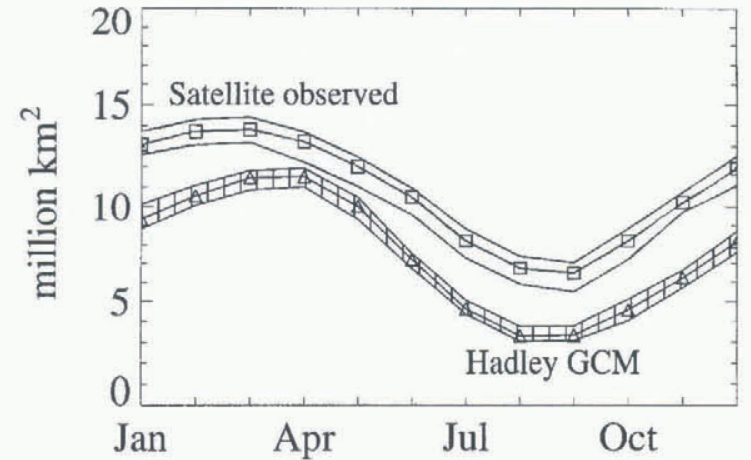

Fig. 1. Arctic sea-ice area from the Hadley GCM and SMMR/SSMI observations. Symbols show the 15 year mean, and shaded regions show the variability.

sea ice by the model, the surface-energy budget for Hudson Bay is investigated in the next section.

\section{SURFACE-ENERGY BUDGET OF HUDSON BAY}

Parameters relevant to the energy budget of Hudson Bay are shown in Figure 3. There is excellent agreement between the validation data and the Hadley GCM in August and September, but the failure of the Hadley model to produce sea ice results in overestimated values of surface-air temperature, specific humidity and cloud in the winter months. A comparison of surface fluxes is presented in Figure 4. The Hadley shortwave and longwave fluxes are generally within the range of the DAO and GISS/ISCCP fluxes. The Hadley sensible and latent heat fluxes also agree very well with the validation data for the summer and autumn months (JuneOctober). The formation of ice in November, however, rapidly closes the sensible and latent heat loss. Heat loss from leads has not been included in the validation data, but is likely to be small given that the winter-ice concentration in Hudson Bay is typically greater than $95 \%$. Failure of the Hadley model to produce ice results in a net heat loss from the ocean of up to $200 \mathrm{Wm}^{-2}$ throughout the winter.

\section{DISCUSSION}

In the absence of advection, the ocean-surface temperature is governed by the net surface flux. A simple energy-balance calculation, assuming a mixed-layer depth of $30 \mathrm{~m}$ and an oceanic heat flux of $2 \mathrm{Wm}^{-2}$ Parkinson and Washington, 1979), reveals that the net Hadley heat loss from Hudson Bay is easily large enough to produce sea ice. Sea ice is prevented from forming in the Hadley model by the flux adjustment (shown in Fig. 4), which, when added to the net flux, results in a heat loss that is far too small during the critical freeze-up period. A similar analysis (not shown) reveals that large flux adjustments also restrict ice formation in the Sea of Okhotsk.

The flux adjustment is intended to prevent modelled SSTs from drifting away from the Levitus (1982) climatology. Due to a lack of winter observations, however, the Levitus climatology appears to be inaccurate in sea-ice covered regions. For example, Figure 5 shows December Levitus SST anomalies, defined as the temperature above the freezing point of sea ice in the Levitus data in ice-covered regions. SST anomalies as large as $5^{\circ} \mathrm{C}$ in Hudson Bay and the Sea of Okhotsk translate to flux adjustments of more than $200 \mathrm{Wm}^{-2}$ (Fig. 5b) and explain the failure of the Hadley model to produce ice in these regions. The Levitus SST climatology has recently been updated (Levitus and Boyer, 1994), but very similar SST anomalies persist in the Arctic regions. In the 1994 climatology (not shown), the magnitude of the SST anomaly is slightly reduced in the Sea of Okhotsk but increased in the Kara Sea in winter compared with the 1982 climatology.

The results of this study highlight a problem with the flux-adjustment procedure, arising from inaccuracies in the observed climatology. Even a perfect model will produce erroneous results if the climatology used to calculate flux adjustments is inaccurate. The manner in which errors in the climatology influence the final solution, however, depends on the way in which the model spin-up and flux adjustment is implemented. The Hadley model was spun-up with the atmosphere and ocean coupled, continuously modifying
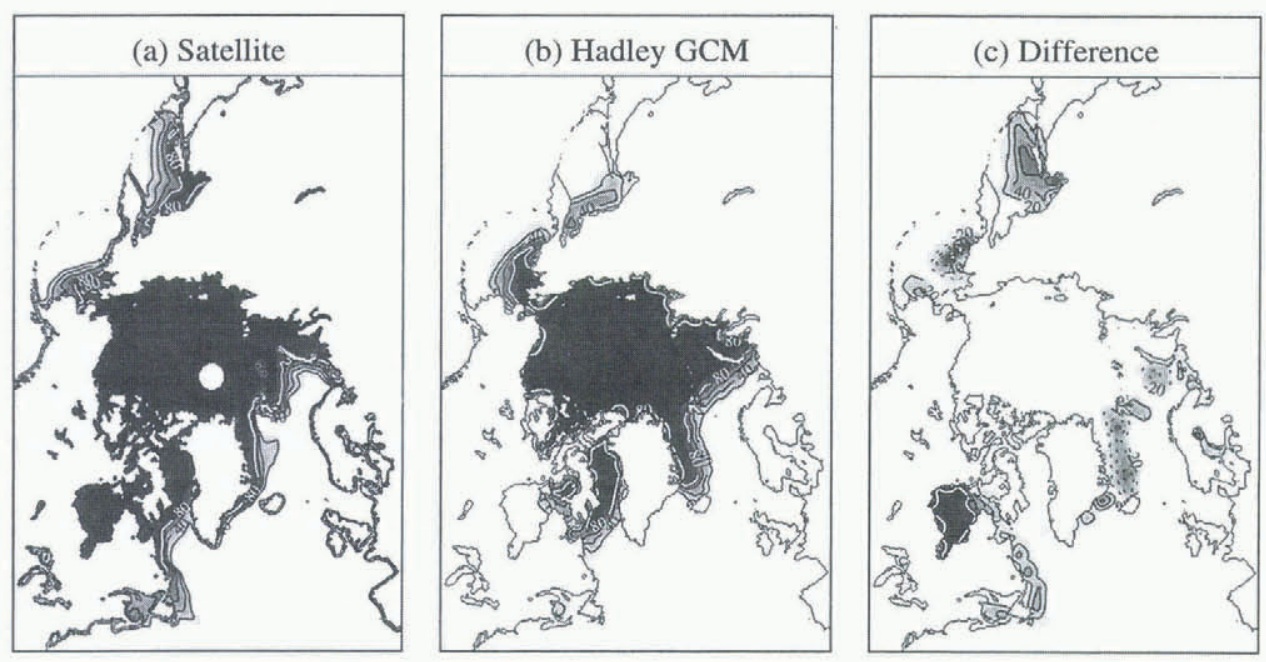

Total ice concentration (\%)

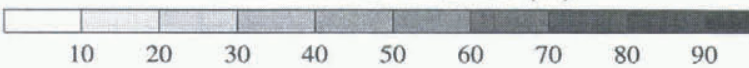




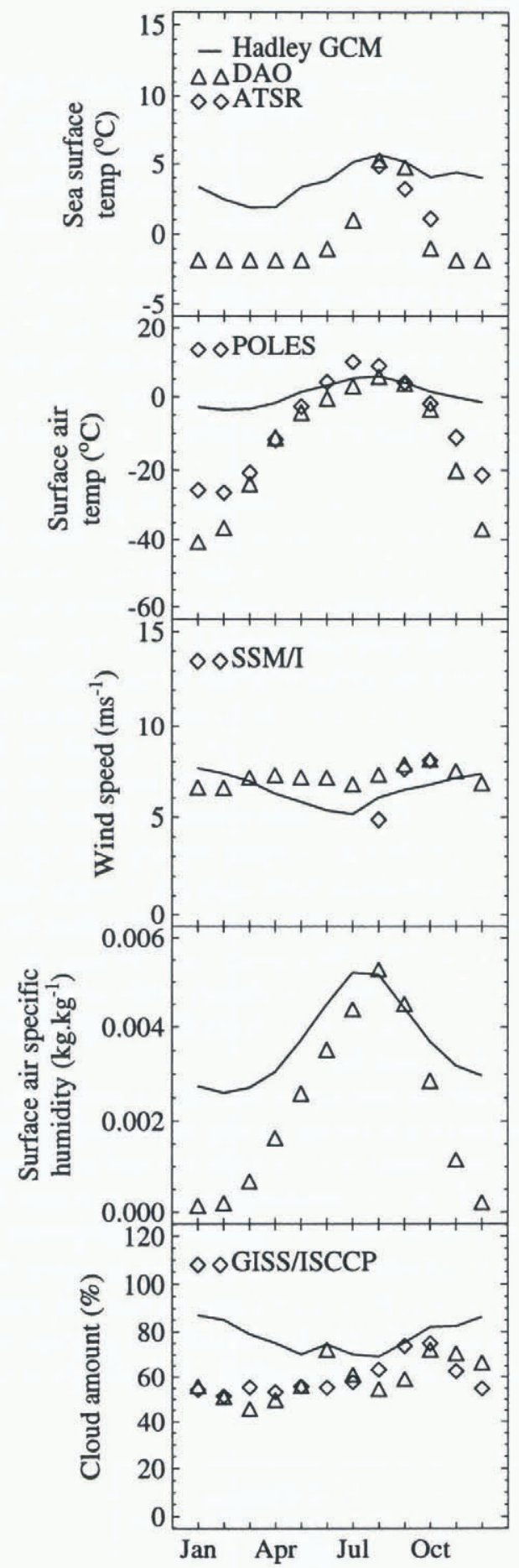

Fig. 3. Evaluation of parameters relevant to the surface-energy budget of Hudson Bay.

the sea-surface temperature and salinity with restoring terms proportional to the difference between modelled and climatological values. These restoring terms were diagnosed at the end of the spin-up, and used as fixed-flux adjustments in subsequent control and climate-change runs.

Other models (Manabe and others, 1991; Cubasch and others, 1992) spin-up the atmosphere and ocean separately, and calculate flux adjustment as the difference between the surface fluxes diagnosed in the atmosphere and ocean models. If, for example, the atmosphere model was spunup with the correct sea-ice climatology instead of the Levitus climatology, then it is likely that the flux adjustment would be completely different from that calculated from the Hadley approach. Indeed, it is possible that the flux adjustment in Hudson Bay could be negative, leading to exces-

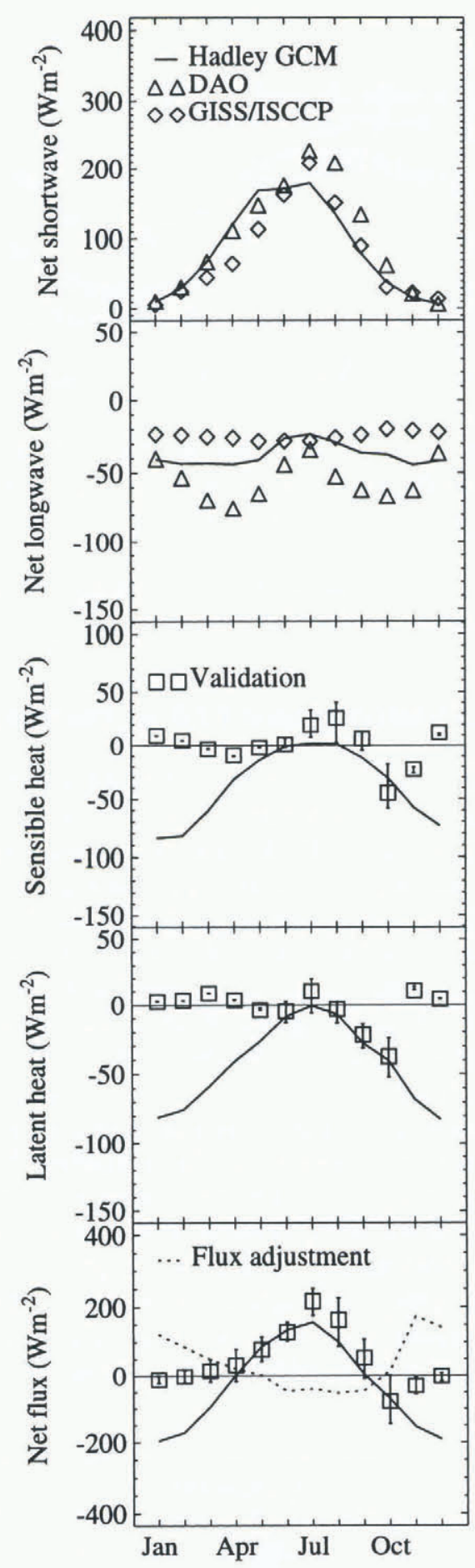

Fig. 4. Evaluation of surface-energy fluxes over Hudson Bay. Fluxes towards the surface are positive.

sive ice build-up. The point is that the flux adjustment, however implemented, is likely to produce erroneous results if it is based on an inaccurate climatology. Furthermore, while the errors in the Levitus SST climatology are relatively large in sea-ice covered regions of the Arctic, it is possible that much smaller errors occurring on a global scale might have a significant effect on the predicted climate. Future work should therefore be aimed both at improving the accuracy of global climatologies, and at improving the accuracy of climate models so that flux adjustment may be eliminated.

Failure of the Hadley model to produce enough sea ice in Hudson Bay and the Sea of Okhotsk does not explain the underprediction of the total sea-ice area in the summer (Fig. 1), because these regions are not ice-covered during 

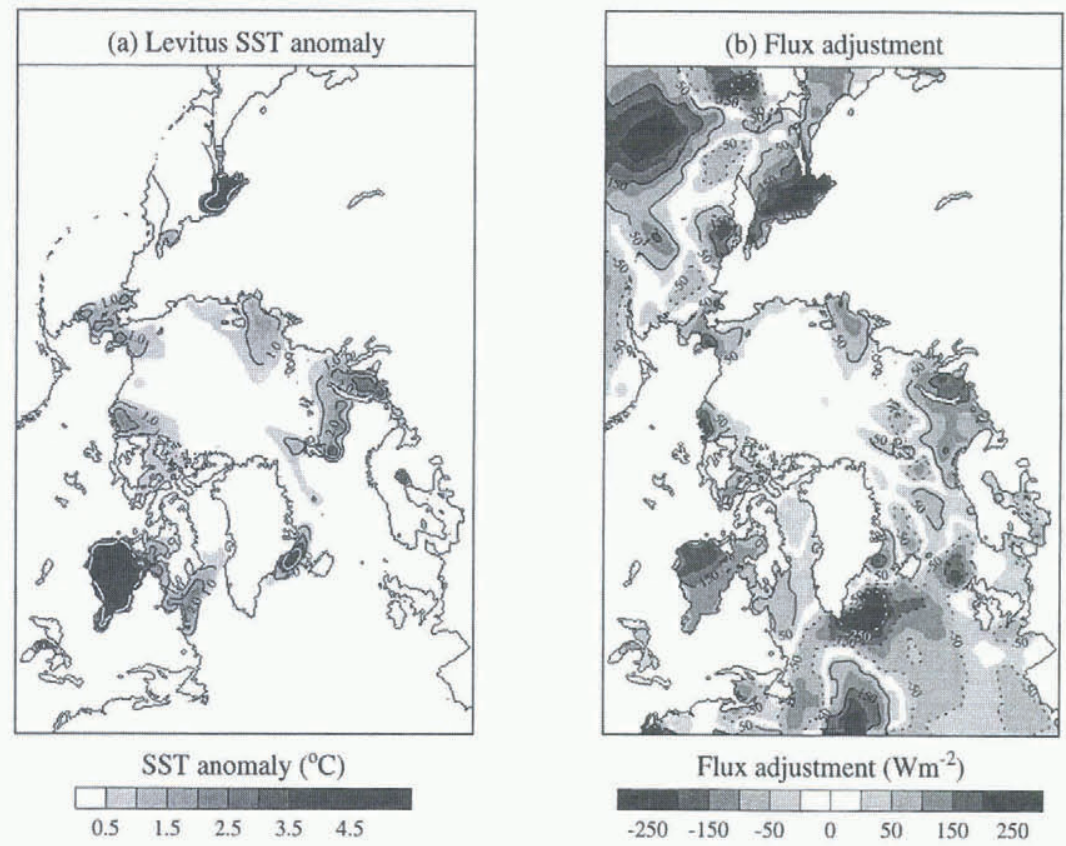

Fig. 5. Levitus SST anomaly (a), defined as temperature above freezing point of sea ice in ice-covered regions, and Hadley GCM flux adjustment ( $b$ ) in December. Negative values are shown by dotted contours.

the summer. The winter ice in the Beaufort Sea is $<2 \mathrm{~m}$ thick in the Hadley model, compared with measured thicknesses $>4 \mathrm{~m}$ (Bourke and McLaren, 1992). It would appear, therefore, that the winter ice is too thin in the Hadley model, enabling too much to melt away in the summer. Further work is required to establish the extent and cause of this underprediction of ice thickness.

\section{CONGLUSIONS}

An evaluation of Arctic sea ice predicted by the Hadley GCM against passive-microwave sea-ice concentrations reveals that, while the seasonal cycle is reasonably well reproduced, the Hadley model underestimates the total area of sea ice by about $3 \times 10^{6} \mathrm{~km}^{2}$ throughout most of the year. Most of the error in winter ice area is accounted for by the failure of the Hadley model to produce ice in Hudson Bay and the Sea of Okhotsk. As a consequence, the heat input to the atmosphere from Hudson Bay alone is too large by up to 0.2 PW during the winter. The underestimated ice concentration in Hudson Bay and the Sea of Okhotsk was found to be caused by inaccuracies in the Levitus (1982) SST climatology on which flux adjustments are based. Although it would be relatively easy to correct climatological SSTs in ice-covered regions (by resetting them to the freezing point of sea ice), and hence overcome some of the problems reported here, it is possible that flux adjustment based on uncertain climatological SSTs in other regions might lead to significant errors in the predicted climate. It is therefore important to develop improved climatologies, and, in the long term, models accurate enough not to require flux adjustment.

\section{ACKNOWLEDGEMENTS}

The authors wish to thank the following for producing and distributing data: the Data Assimilation Office (Code 910.3) and the Distributed Active Archive Centre (DAAC) Code 902.2) at the Goddard Space Flight Centre, Greenbelt, MD,
U.S.A., under the sponsorship of NASA's Mission to Planet Earth program; the EOSDIS NSIDC DAAC, University of Colorado at Boulder, CO, U.S.A.; the Physical Oceanography DAAC, Jet Propulsion Laboratory, Pasadena, CA, U.S.A.; the ATSR processing team at Rutherford Appleton Laboratory, UK (funded by NERC); the ISCCP and Goddard Institute of Space Studies, MD, U.S.A.; and the POLES team, University of Washington, Seattle, U.S.A. The authors are grateful to colleagues at MSSL and the Hadley Centre, particularly H. Cattle, R. Wood and C. Gordon, for useful suggestions and discussions. The reviewers, particularly M. Morales Maqueda and G. Flato, are thanked for providing comments that improved this paper. The GCM integrations were performed with the aid of funding from DOE contract PECD 7/12/37. This work was funded by NERC, grant number GR3/9600.

\section{REFERENCES}

Aagaard, K., J. H. Swift and E. C. Carmack. 1985. Thermohaline circulation in the Arctic mediterranean seas. 7. Geophys. Res., 90 C3), $4833-4846$.

Bourke, R. H. and A. S. McLaren. 1992. Contour mapping of Arctic Basin ice draft and roughness parameters. J. Geophys. Res., 97 (C11), 17,715-17,728.

Bryan, K. 1969. Climate and the ocean circulation. III. The ocean model. Mon. Weather Rev., 97 (11), 806 827.

Cavalieri, D. J., P. Gloersen and W. J. Campbell. 1984. Determination of sea ice parameters with the NIMBUS 7 SMMR. 7. Geoplyys. Res., 89 (D4), $5355-5369$.

Cubasch, U. and 6 others. 1992. Time-dependent greenhouse warming computations with a coupled ocean-atmosphere model. Climate Dyn., 8 2), 5569.

Fletcher, J. O. 1965. The heat budget of the Arctic basin and its relation to climate. Santa Monica, CA, Rand Corporation. (Technical report R-444-PR.

Halpern, D. and 6others. 1995. An atlas of monthly mean distributions of SSM/Isurface wind speed, AVHRR $/ 2$ sea surface lemperalure, AMI surface wind velocity, TOPEX POSEIDON sea surface height, and ECMIWF surface wind velocity during 1993. Pasadena, CA, Jet Propulsion Laboratory. (JPL Publication 95-3.

Hibler, W. D., III. 1979. A dynamic thermodynamic sea ice model. J. Phys. Oceanogr., 9 (7), 815-846.

Ingram, W. J., C. A. Wilson and J. F. B. Mitchell. 1989. Modeling climate change: an assessment of sea ice and surface albedo feedbacks. F. Geophys. Res., 94 (D6), $8609-8622$.

Johns, T. C. and 7 others. 1997. The second Hadley Centre coupled oceanatmosphere GCM: model description, spinup and validation. Climale Dyn., 13, 103-134 
Jones, M. S., M. A. Saunders and T. H. Guymer. 1996. Global remnant cloud contamination in the ATSR data: source and removal. . \%. Geophys. Res., 101 (C5), 12,141-12,147.

Levitus, S. 1982. Climatological atlas of the world ocean. Rockville, MD, U.S. Department of Commerce, National Occanic and Atmospheric Administration. (NOAA Professional Paper 13.

Levitus, S. and T. P. Boyer. 1994. World ocean atlas 1994. Vol. 4. Temperature. Rockville, MD, U.S. Department of Commerce. National Oceanic and Atmospheric Administration.

Manabe, S., R. J. Stouffer, M.J. Spelman and K. Bryan. 1991. Transient response of a coupled ocean - atmosphere model to gradual changes of atmospheric $\mathrm{CO}_{2}$. Part I: Annual mean response. 7. Climate, 4 (8), 785-818.

Maykut, G. A. 1978. Energy exchange over young sea ice in the central Arctic. 7. Geophys. Res., 83 (C7), 3646-3658.

Murphy, J. M. 1995. Transient response of the Hadley Centre coupled ocean-atmosphere model to increasing carbon dioxide. Part I. Control climate and flux adjustment. f. Climate, 8(1), 36-56.

National Snow and Ice Data Center (NSIDC). 1989-. DMSP SSM/I brightness temperature and sea ice concentration grids for the polar regions. Boulder, CO, University of Colorado. Cooperative Institute for Research in Environ- mental Sciences. National Snow and Ice Data Center, Distributed Active Archive Center:

Parkinson, C. L. and W. M. Washington. 1979. A large-scale numerical model of sea icc. 7. Geophys. Res., 84 (C1), 311-337.

Rossow, W. B. and Y. C. Zhang. 1995. Calculation of surface and top of atmosphere radiative fluxes from physical quantities based on ISCCP data sets. 2. Validation and first results. 7. Geophys. Res., 100 (D1), 1167-1197.

Sausen, R., K. Barthel and K. Hasselmann. 1988. Coupled ocean-atmosphere models with flux correction. Climate Dyn., 2 (3), 145-163.

Schubert, S. D., R. B. Rood and J. Pfaendtner. 1993. An assimilated data set for earth science applications. Bull. Am. Meteorol. Soc., 74(12), 2331-2342.

Semtner, A. J., Jr. 1976. A model for the thermodynamic growth of sea ice in numerical investigations of climate. 7. Phys. Oceanogr, 6 5), 379-389.

Zavody, A. M., C.T. Mutlow and D.T. Llewellyn-Jones. 1995. A radiative transfer model for sea surface temperature retrieval for the Along-Track Scanning Radiometer (ATSR). J. Geophys. Res., $100(\mathrm{Cl}), 937-952$.

Zhang, Y. C., W. B. Rossow and A. A. Lacis. 1995. Calculation of surface and top of atmosphere radiative fluxes from physical quantities based on ISCCP data sets. 1. Method and sensitivity to input uncertainties. 7 . Geophys. Res., $100(\mathrm{Dl}), 1149-1165$. 